\title{
Eating Disorders and Disordered Eating in Different Cultures
}

\section{Citation}

Weiss, Mitchell G. 1995. Eating Disorders and Disordered Eating in Different Cultures.

Psychiatric Clinics of North America 18 (3): 537-553.

\section{Permanent link}

http://nrs.harvard.edu/urn-3:HUL.InstRepos:35642709

\section{Terms of Use}

This article was downloaded from Harvard University's DASH repository, and is made available under the terms and conditions applicable to Other Posted Material, as set forth at http:// nrs.harvard.edu/urn-3:HUL.InstRepos:dash.current.terms-of-use\#LAA

\section{Share Your Story}

The Harvard community has made this article openly available.

Please share how this access benefits you. Submit a story. 
EATING DISORDERS AND DISORDERED EATING IN DIFFERENT CULTURES

\author{
Mitchell Weiss, M.D., Ph.D. \\ Senior scientist \\ Department of Public Health and Epidemiology \\ Swiss Tropical Institute \\ $\underline{\text { Address }}$ \\ Swiss Tropical Institute \\ Department of Public Health and Epidemiology \\ Socinstrasse 57 , \\ $\mathrm{CH}-4002$ Basel \\ SWITZERLAND \\ Tel : \\ Fax: \\ $\begin{array}{lllll}41 & 61 & 284 & 82 & 83\end{array}$ \\ E-Mail: \\ $\begin{array}{lllll}41 & 61 & 271 & 79 & 51\end{array}$ \\ mweiss@camtwh.eric.on.ca \\ Accepted for Publication in: \\ PSYCHIATRIC CLINICS OF NORTH AMERICA
}

Revised November 10,1994 
EATING DISORDERS AND DISORDERED EATING IN DIFFERENT CULTURES

\section{SYNOPSIS}

The prevailing cultural analysis of eating disorders emphasizes the impact of a drive for thinness that follows a Western cultural ideal of feminine beauty. The success of this theory has paradoxical implications, highlighting the role of culture but hampering diagnosis of eating disorders and cross-cultural research in some settings. This critical review considers historical accounts of eating disorders, current research and clinical experience, and related patterns of altered eating behaviors, mainly fasting and hunger strikes, in religious, social, and political contexts apart from medicine. From this broader perspective it summarizes and critically assesses current diagnostic criteria for anorexia nervosa and bulimia nervosa. An agenda for cultural research capable of distinguishing local cultural features and core concepts of eating disorders concludes the review. 
EATING DISORDERS AND DISORDERED EATING IN DIFFERENT CULTURES

The two most common eating disorders, anorexia nervosa (AN) and bulimia nervosa (BN), are serious psychiatric conditions with potentially fatal consequences. Estimates of morbidity and mortality from AN range from $4 \%$ to $8 \% .{ }^{57} \mathrm{AN}$ and $\mathrm{BN}$ occur most frequently in North America, Western Europe, and Japan, where they are characterized mainly by eating too much or too little to an extreme considered pathological, sometimes associated with laxative abuse or self-induced vomiting, and identified in DSM-IV with distorted ideas about appropriate body weight and one's own body image. Although incidence rates in the general population have been difficult to study, estimates of the prevalence of eating disorders among high risk female students range from $1 \%$ to $4 \% .{ }^{1,48}$ About $5 \%$ to $10 \%$ of patients are male, and homosexuals appear to be at greater risk than heterosexual men. ${ }^{32} \mathrm{AN}$ and $\mathrm{BN}$ are increasing not only among previously identified high risk groups in the West ${ }^{54}$ but also in developing countries and among minorities in developed countries. 56,18,20 A third eating disorder that also affects adults, pica, is characterized by ingesting inappropriate substances, rather than excessive or reduced quantities of food.

Historically, anorexia provided a focus for the professional definition of eating disorders, and among them it remains the principal focus of clinical attention. This cross-cultural review reflects this emphasis and considers bulimia, a more recently defined clinical disorder, in relation to anorexia. Current clinical discussions of $\mathrm{AN}$ and $\mathrm{BN}$ regard them as multifactorial disorders resulting from an interaction of individual, familial, and cultural influences. ${ }^{28}$ Increasing rates of $\mathrm{AN}$ and $\mathrm{BN}$ over the last several decades restricted to some parts of the world have motivated a social and cultural analysis, which however productive may also paradoxically have stifled crosscultural study of eating disorders. Western esthetics that value slimness as an ideal of feminine beauty have been so influential on the theory explaining the distribution of eating disorders across cultures that these values have been incorporated into the professional definitions of anorexia nervosa and bulimia nervosa. 
Although William Stout Chipley described sitomania as a "phase of insanity" characterized by "intense dread of food" in 1859 in the American Journal of Insanity, modern authors usually trace the current concept of anorexia nervosa to Sir William Withey Gull, a London physician who coined the term in 1873, and Charles Lasègue, a Parisian neurologist whose account of l'anorexie hystérique emphasized the psychological affects of the illness on the patient and family. ${ }^{13}$ Subsequently anorexia nervosa and hysterical anorexia came to be used interchangeably. Bulimia, on the other hand, until it was incorporated in DSM-III, was more closely associated with ideas of gluttony as a moral rather than a medical concern.

Similarities between the modern and historical descriptions of clinical anorexia include occurrence predominately in adolescent and young women, the absence of a biomedical lesion, reference to the psychogenic basis of the condition, and associated family conflicts. The emphasis on restlessness and agitation in the historical account is absent in the current criteria. Questions about the organic basis of eating disorders, attributing them to a pituitary lesion, received serious consideration from 1914, but the organic hypothesis proved to be of limited value and has had little influence on the field since the 1930s.

The preoccupation with body weight and body image were absent in Gull's original description of anorexia nervosa, which explained enormous weight loss as a result of obstinate food refusal, loss of appetite, difficulty swallowing, or just eating less. It was not until the 1930s that a German term was introduced, Magersucht (addiction to thinness), reflecting a current feature of the disorder absent from the earlier writing. ${ }^{44}$ Since the 1960s this drive for thinness has become a prominent feature of the disorder. ${ }^{15}$ Cases of the "remarkable fasting girls" in the 19th and early part of this century in Western Europe and North America are described by Brumberg. ${ }^{13}$ Self-starvation resulting from a quest for spiritual piety made them "both a curiosity and medical mystery,"13,p.97 and people wanted to witness their austerities; local entrepreneurs exploited the celebrity status of these anorectics. The attention they attracted and efforts of doctors to explain their ability to survive without food also bridged a conceptual gap to 
complete the transformation of self-starvation from a matter of religious piety to a concern of medical science.

While self-starvation as a rational choice may have been acceptable (and may still be) for autonomous adults, it was more difficult to accept for dependent young women, whose bodies were their families' responsibility, for which they were becoming accountable before the law. The debilitation of these girls and young women not only marked what came to be viewed as a personal affliction but also threatened the stability of bourgeois family life, symbolized by participation in family meals. ${ }^{13}$ Insofar as a medical model could explain and intervene to restore the social order of family life, it became more appealing and compelling.

Frameworks for Social Analysis, Clinical Care, and Comparative Research Western cultural ideals associating thinness and beauty have dominated the social analysis and cross-cultural studies of eating disorders over the past two decades. As a core theme in Western culture, this ideal provides the basis for arguments that anorexia nervosa and bulimia nervosa are culturebound syndromes of North America and Western Europe, which have spread only with Westernization to other cultures. Recognizing the limitations of this paradigm, authors have suggested other explanatory frameworks that may also play an important role (Table 1).

DiNicola distinguishes the culture-bound syndrome from the culturechange syndrome associated with urbanization in developing countries and immigration to developed countries. ${ }^{20}$ Recognizing the susceptibility of adolescents to the influence of public figures and peers, Hilde Bruch described a copycat phenomenon, which may account for the spread of eating disorders. Shorter argues that efforts of the medical establishment to control eating disorders may in fact have afforded them the notoriety responsible for their spread. ${ }^{65}$

These frameworks, focusing on forces within society at large, have been elaborated primarily from social and historical studies of eating disorders. Clinical experience has focused attention on more immediate social and psychological formulations. Disturbed family dynamics have been associated 
with anorexia since at least the 19th century. Efforts to negotiate interpersonal boundaries and establish a sense of identity and autonomy, defined as major developmental tasks in Western cultures, have motivated the development of family therapies, which have made eating disorders a principal area of concern from the outset.

Psychodynamic models argue that in some cases willful absention from eating represents an effort to forestall sexual maturity, repress sexual drives, and prevent development of an appealing female figure, which by attracting the attention of boys would bring an unwanted end to childhood. ${ }^{17}$ The apparent contradiction between explanations driven by the appeal of thinness as a mark of beauty and a contradictory fear of becoming beautiful is paradoxical.

Ballet dancing, figure skating, gymnastics, and possibly other sports and artistic activities for which a lean body build is required to enhance performance have been associated with anorexia and bulimia. ${ }^{33,29 !}$ The demands and competitive nature of these activities greatly magnify whatever pressures exist in society to conform to a slim ideal; low calorie dieting, food faddism, and irrational use of nutritional supplements are common among dancers. ${ }^{14 \%}$ Colleagues serving as mentors and exemplars may provide an introduction to laxative abuse and methods of self-induced vomiting that blurs a subtle distinction between required dieting and overvaluation of thinness. In such settings where body weight and some degree of dieting are a normative concern, the momentum of dieting may itself become compelling, independent of whatever motive initiated the process.

Comorbidity with other psychiatric conditions, especially depression, ${ }^{36 "}$ and other factors, such as a history of child abuse, sexual or physical, have also been associated findings more closely linked with bulimia than anorexia. ${ }^{61,39}$ In addition to their clinical utility, the professional explanatory models listed in Table 1 provide a framework for cross-cultural research to identify core features of disordered eating behaviors in various clinical and sociocultural settings; they also provide a starting point for needed studies of local illness meanings. 
Culture-Bound Disorder and Culture-Bound Theory

The analysis of anorexia nervosa as a culture-bound syndrome in societies where an overvaluation of thinness is prominent resulted both from the reported low incidence of eating disorders in developing countries and from the need for examples of culture-bound disorders of Western cultures. The "new cross-cultural psychiatry" asserts that cultural constructions of psychiatric illness are pervasive, not restricted to exotic settings far away from the Western societies that engendered psychiatric theory. ${ }^{40,46}$ Previously, the term culture-bound disorders, coined by P.M. Yap, ${ }^{75}$ had meant exotic clinical curiosities. Elevating obesity to the status of a social malady ${ }^{60}$ and both $\mathrm{AN}$ and $\mathrm{BN}$ to status of clinical disorders provided needed examples showing that the concept of culture-bound syndrome was more broad-based and equitable than earlier accounts suggested. $4 \$, 68,58$

More so than for other psychiatric problems, mental health professionals have scrutinized cultural contexts of eating disorders over the past several decades. Cultural hypotheses provided a palatable alternative to unproductive psychoanalytic theories of oral impregnation, which dominated the field in the 1940s and 1950s. For example, Felix Deutsch and colleagues explained AN as the result of a "fantasy of oral impregnation, with the mouth as the receptive organ of food symbolizing conception, the gastrointestinal tract symbolizing the womb and the cessation of menstruation being associated with pregnancy."19, quoted by 50, p619 Psychodynamic explanations of anorexia as an effort to avoid sexual maturity and a womanly figure appear to be at odds with the sociocultural theory that anorexia is driven by slimness as an ideal. If that is so, and if the aim is to avoid the ideal, one might expect overeating and obesity instead.

Hilda Bruch decried unitary psychoanalytic theories, which focused too much on the symbolic significance of disturbed eating, unconscious problems, fantasies, and dreams, and too little on conflicts related to establishing identity, negotiating disturbed family dynamics, and improving nutrition, the most immediate concern. ${ }^{11,12}$ She also advanced a social analysis of eating disorders that remains current, explaining their increase over the past several decades as the result of changing sociological attitudes and changing 
roles of women in society.

Attention to the influence of a drive for thinness as a cultural ideal of feminine beauty motivated a number of cultural analyses of eating disorders. Ritenbaugh argues that obesity is a Western culture-bound syndrome. ${ }^{60}$ Littlewood provides additional anthropological support to the premise that women's bodies are particularly susceptible to social conventions, noting that "Western women achieve a social identity through their bodies in a way men do not"; elaborating the position of anthropologist Victor Turner, he argues that they "may 'possess' their bodies phenomenologically, but they do not 'own' them," as men do.47 Janice Boddy, also an anthropologist, suggests that the vulnerability of women's bodies to socially sanctioned (or required) disfigurement represents a pervasive social dynamic arising from a political aspect of embodiment, ${ }^{63}$ which helps to explain both the occurrence of anorexia among Western women and socially accepted practices of female circumcision, infibulation, or clitoridectomy among some Africans. ${ }^{9}$ In her discussion of female circumcision and genital surgery in Egypt and the Sudan, showing how easy it is to accept familiar practices and reject those that are unfamiliar, Boddy recounts the surprise of an African diplomat at a dinner party in Khartoum when he learned that Western white women actually cultivate a figure he had mistaken for emaciated. "But where does she put her food?" he asked.

Social analysis from a feminist perspective suggests that eating disorders result from an overvaluation of thinness as an ideal that few women can achieve. ${ }^{24}$ This literature offers various models to explain how cultural values produce eating disorders. Self-starvation and binging represent one or a combination of responses to this ideal. The need to come to terms with it explains why women's bodies are subjected to adornments, alterations, and mutilations, ranging from make-up to corsets, pierced ears, and infibulation or other forms of genital mutilation in extreme cases. ${ }^{31,69}$ Culturally based overvaluation of slimness leads to eating disorders as a result of overzealous efforts to conform (AN) or frustration from an inability to meet the standard (BN). The feminist critique associates an oppressive standard of feminine beauty with a restricted range of opportunities available to young women. It 
highlights the confrontational relationship of the adolescent girl or young woman at highest risk for eating disorders with her family and the male doctors who may be treating her. Efforts to establish control refer to a social context beyond the family, extending into a male-dominated society. Eating disorders researchers have also studied this apparent relationship between changing cultural ideals of beauty and increasing rates of eating disorders in North America and Western Europe, which link beauty, slimness, dieting, anorexia, and bulimia. Garner and Garfinkel demonstrated the trend toward increasing slimness as a standard of feminine beauty in a study of the physical measurements of women photographed for Playboy Magazine centerfolds and Miss America beauty pageant winners. ${ }^{29 !}$

Nevertheless, even in North America there are limits to the utility of this paradigm. Steiger cautions, "Anyone who works with large numbers of AN sufferers knows that this disorder is not uniformly about a desire to be thin."66 Fichter and colleagues, arguing for the social change hypothesis, concluded that the process of adaptation among immigrants may lead to anorexia even in the absence of a cultural drive for slimness. ${ }^{25}$ Controversial research by Mumford and co-workers in Bradford, England, found that among Asian girls scoring on tests of disordered eating--the 26-item Eating Attitudes Test (EAT-26) and the Body Shape Questionnaire (BSQ)--disordered eating was related more to a traditional, rather than Westernized, cultural orientation. ${ }^{51}$ They attributed these results to the stress of cultural adjustment, rather than the influence of Western cultural values of feminine beauty. DiNicola advocates a new concept, culture-change syndrome, that would account for these findings and leave the concept of culture-bound syndrome intact by creating another category for cases outside settings where the "bound" disorder is supposedly restricted. ${ }^{20}$

The culture-change hypothesis, however, is also problematic. A case series of 4 patients with AN from Bangalore, India, reported that 3 of them came from very traditional households. "The youngest patient had never been sent to school by her illiterate parents and had not even traveled outside of her village until she was forced to do so by her symptoms." ${ }^{26}$ King and Bhugra found unusually high scores on a rural sample of 580 schoolgirls in a small 
industrial town in North India, the highest reported prevalence of abnormal eating attitudes from use of the EAT anywhere. ${ }^{38}$ The significance of these data is unclear, however, as the authors dismissed their own and the comparable findings of Mumford and Whitehouse from previous studies in Bradford, England, ${ }^{52,53 \$}$ as artifacts arising from inappropriate adaptation of the instrument.

Shorter offers another alternative to the slimness-as-cultural-ideal hypothesis to explain increased rates of anorexia and bulimia in Western societies. He argues that as eating disorders have come to be recognized as legitimate expressions of distress and specialty clinics have proliferated and publicized these conditions, they have altered the sociocultural patterning of distress and expressions of illness in Western societies. Paradoxically, this process has promoted eating disorders as a result of efforts to identify and treat them. The increased publicity and development of what he terms the "eating disorder industry" has transformed the expression of illness over time into the current concepts of $\mathrm{AN}$ and $\mathrm{BN}$ by reconfiguring somatic symptoms from the same pool that engendered hysteria and neurasthenia in the past. If that is so, as rates of eating disorders increase in East Asia, one might expect to find complementary decreasing rates of neurasthenia. ${ }^{70}$

Other psychiatric researchers have also identified similarities between anorexia and hysteria. Bemporad and colleagues state that both are expressions of age-specific conflicts, that is, an effort to avoid the responsibilities of adult life by means of culturally structured illness models associated with particular familial conflicts. ${ }^{7}$ As such they represent "exercises in power by the powerless." They review other academic studies comparing hysteria and anorexia ${ }^{30,55,67,64}$ and quote an article in Life magazine from February 1982, which states: "Hysteria has almost disappeared, but if there is an equivalent today it is anorexia." Shorter's discussion of the influence of eating disorder specialty clinics on the expression of illness provides an alternative account of the mechanism by which Westernization, associated with urbanization and immigration, affects rates and patterns of eating disorders. It is the publicity from an emerging medical infrastructure with its high profile in the 
popular culture that provides a medically validated model to experience distress. Consequently, efforts to recognize and treat disorders that are assumed to increase under the influence of Western culture may themselves have unintentionally affected the expression and prominence of eating disorders.

Imitative behavior, the copycat phenomenon described by Bruch, may also play a role, complementing effects of the medicalization of disordered eating. Fahy and colleagues discuss the case of an Ethiopian woman with anorexia and psychogenic vomiting that began after she was tortured in Ethiopia. ${ }^{23}$ Vomiting began after a blood-stained rag had been stuffed in her mouth to stifle her screams. During her hospitalization for anorexia, vomiting, and weight loss in a unit with patients suffering from anorexia nervosa, she acquired "anorectic attitudes" about becoming fat, her body shape, and her desire to maintain an abnormally low weight. The authors suggest that the influence of other anorectic inpatients may have accounted for her increasing concerns about body image and a new desire to remain inordinately thin.

\section{Epidemiology across Cultures}

Although differences in diagnostic criteria, clinic and community sampling strategies, screening methods, and choice of demographic groups for reporting base rates complicate precise epidemiological comparisons, a recent review concluded rates of eating disorders among various socioeconomic and ethnic groups in North America and in other societies worldwide are increasing. ${ }^{56}$ The increase in Japan is particularly striking. Findings showing that rates are increasing among African-Americans in the United States, working-class females in Hong Kong, and among a broader range of other minority and socioeconomic groups ${ }^{35,59,45,56}$ challenge ideas about the association of achievement-oriented, upper-middle-class families from ethnic backgrounds where food is a preferred means of expressing feelings.

Considering the low rates in Hong Kong from a community study with the Diagnostic Interview Schedule (DIS), which indicated a lifetime prevalence of $.03 \%$, Lee discusses reasons why the interpretation of such findings is not necessarily straightforward for international studies. ${ }^{42}$ Cultural patterns of distress, help-seeking preferences, and the inattentiveness of clinicians to 
eating disorders where the Western literature does not indicate they are likely to be found may result in underestimates of the significance of disturbed eating behaviors in many non-Western countries.

Lee's clinical research on eating disorders in Hong Kong has demonstrated that the Western criteria of DSM-III-R, which for the most part have remained unchanged in DSM-IV, are inadequate. ${ }^{43,45}$ Typical features of Western cases, which have been incorporated into the professional diagnostic criteria, require fear of gaining weight and distorted body image; these were notably lacking among patients in Hong Kong with symptoms of anorexia. The researchers found that premorbid obesity and pressure to pursue slimness for beauty among anorectics were uncommon. "Our patients usually had not heard of anorexia nervosa as a psychiatric disorder and were thus not [the] 'me-too' anorexics" that Hilda Bruch described. ${ }^{10,45}$ Social stressors associated with anorexia in their group included examination pressure, loss of relationships, overprotective mothers, parental conflicts, sibling rivalry, physical illness, and distant fathers.

In an expanded follow-up study, constituting the largest East Asian series of case studies of anorexia outside of Japan, Lee and colleagues reported that 41 of 70 patients (58.6\%) gave no indication that concern about avoiding fatness played any role whatsoever in their disorder, despite a systematic inquiry investigating this question. ${ }^{43}$ They explained their fasting as the result of epigastric bloating (31.4\%), lack of appetite (15.7\%), or just eating less $(12.9 \%)$. The investigators concluded that culturally valued thinness is not a core feature of the disorder, suggesting rather that it operates as a pathoplastic factor, influencing the manifestation of anorexia in cultures where such values are significant.

In India, Khandelwal and Saxena also report that a clear body image disturbance or fear of becoming fat is hardly ever seen among their anorectic patients. ${ }^{37 "}$ Their findings refer to associated functional or clear conversion symptoms consistent with Shorter's assertion that AN and BN are not necessarily distinct disorders, but rather a variant of the broader class of functional somatic conditions that includes hysteria. 


\section{Diagnosis of Eating Disorders}

Since the late 1960s eating disorders have commanded increasingly prominent status in the psychiatric nomenclature of the American Psychiatric Association (Diagnostic and Statistical Manual, DSM) and the World Health Organization (International Classification of Diseases, ICD). DSM-II includes "feeding disturbance" under a category of Special Symptoms Not Elsewhere Classified. ${ }^{5}$ It says nothing more about it than, "An example might be anorexia nervosa."

ICD-9 included a more specific category for anorexia nervosa with most of the features of the current clinical criteria, (e.g., refusal to eat, weight loss, amenorrhea, alternation with periods of overeating). ${ }^{74}$ A notable exception, however, was the absence of any mention of attitudes toward body image. A category of overeating, later elaborated as bulimia in ICD-10, was included among a broad group of unspecified disorders of eating.

ICD-10 includes an enhanced section on eating disorders under Behavioral Syndromes. ${ }^{73}$ The criteria for AN emphasize "body-image distortion in the form of a specific psychopathology whereby a dread of fatness persists as an intrusive, overvalued idea" (criterion C). The criteria for BN similarly specify "a morbid dread of fatness."

DSM-III included categories of anorexia nervosa and bulimia under Diagnostic Categories of Infancy, Childhood, or Adolescence. ${ }^{4}$ Despite its proclaimed atheoretical orientation, DSM-III introduced a psychodynamic rationale in the definition of AN in criterion A, "intense fear of becoming obese, which does not diminish as weight loss progresses," and criterion B, "disturbance of body image, e.g., claiming to 'feel fat' even when emaciated," but not for bulimia. In DSM-III-R, however, "persistent overconcern with body shape and weight" was introduced among the criteria for a revised category of bulimia nervosa. ${ }^{3}$ Fear of becoming "fat" replaced fear of becoming "obese" in the criteria for AN.

DSM-IV moved $\mathrm{AN}$ and $\mathrm{BN}$ to a more prominent position as an independent section of the manual exclusively on eating disorders. ${ }^{2}$ Other eating disorders remained in the section on Disorders Usually First Diagnosed in Infancy, Childhood, or Adolescence; this section includes pica, which in some 
cultures is a disorder affecting pregnant women as well as children. ${ }^{41}$ Epidemic pica has also been reported among aboriginal women past child-bearing age in Australia. ${ }^{21}$ Criterion B of AN remained unchanged, keeping "intense fear of gaining weight or becoming fat" as an essential feature of the disorder, despite questions arising from experience in non-Western cultures.

The text in the description of AN under Specific Culture, Age, and Gender Features of the Disorder addressed this issue, stating, "In some cultures, disturbed perception of the body may not be prominent and the expressed motivation for food restriction may have a different content, such as epigastric discomfort or distaste for food."2, p543 Readers may find this passage confusing, however, since such persons could not be diagnosed with AN because they would not meet the criteria for "intense fear of gaining weight or becoming fat."

Based on the conclusion in a review by Hsu and Lee, published in the American Journal of Psychiatry, ${ }^{34}$ the Culture and Diagnosis Committee, an NIMH-sponsored group organized to advise the DSM-IV Task Force on cultural issues, made a recommendation to minimize the impact of an overly rigid criterion that may yet prove to be a culture-specific associated finding. The committee suggested that the category of Eating Disorder Not Otherwise Specified (NOS) should at least include among the examples listed a disorder that meets all categories of AN except the fear of gaining weight. This recommendation, which was not adopted in DSM-IV, would have facilitated research on this important subgroup to clarify the nosology and the cultural context of anorexia nervosa. It would also have complemented the two examples that already refer to anorexia under Eating Disorder NOS (i.e., a condition meeting all the criteria for AN except that the individual has regular menses, and all the criteria for AN except that the individual's weight remains in the normal range).

Criterion D for BN similarly stipulated that "self-evaluation is unduly influenced by body shape and weight," but an experimental category of binge eating disorder, which is included among criteria sets for further study in Appendix B, makes no mention of body shape or weight. Cross-cultural studies that raise questions about how to interpret low rates of eating disorders in 
non-Western cultures indicate that researchers are likely to use this category effectively, as they would an analogous category for anorexia if it were available.

Attempting to remedy the problems of the overly culture-specific DSM criteria for AN, Sing Lee proposed a set of 5 criteria for a more culture-free diagnosis (Table 2). ${ }^{44}$ The innovative features are in criteria $B$ and $C$. Instead of the DSM-IV criterion B that specifies fear of gaining weight and becoming fat, Lee suggests phenomenological criteria based on what patients do to achieve or maintain dramatic weight loss. Similarly, criterion C would replace the DSM-IV requirement of disturbed body image with one or more of various alternative motives for pathological fasting, based on extensive research and clinical experience.

Religious, Social, and Political Contexts of Fasting and Anorexia

Self-starvation may provide a means to exercise power and control in families and societies. Anorexia nervosa represents a subset of a broader range of self-starvation behaviors that include expressions of social and political protest, self-purification, and religious piety. Asceticism and religious fasting, as Banks suggests, may continue to play an important role in the dynamics of anorexia. ${ }^{6}$ Other forms of disturbed eating behaviors are less likely to be considered pathological, however, despite similarities to the psychiatric conditions, unless they lead to medical complications requiring life-saving interventions. These include self-starvation as a means of political or social protest, fasting as a means of religious purification, and fasting as a culturally sanctioned means of committing suicide.

Various religions institutionalize fasting, which may serve both as an expression of piety and to validate group membership. Judaism directs followers to fast on Yom Kippur, a day of prayer and atonement. Islam enjoins fasting in the daylight hours of Ramadan, the 9th month of the Islamic calendar. Hindus may choose to fast, either completely or by restricting certain foods at specified times during the week, month, or year. Elderly Jains afflicted by illness and no longer able to fulfill obligatory religious duties were permitted to consider the option of ritualized self-starvation, a 
fatal practice known as sallekhanā. Case reports suggest that prolonged religious fasting during the Islamic month of Ramadan may be associated with the onset of anorexia nervosa. ${ }^{8,49}$

Fasting as a means of social protest through passive resistance combines elements of religious purification and coercion to advance a cause. Mahatma Gandhi proclaimed a "fast unto death" from time to time very effectively during the freedom struggle to liberate India from colonial rule. His autobiography indicated that vegetarianism, his choice of foods, regular fasting for religious purification, and fasting as social protest all played an important role in his lifelong "experiments with truth" (saty āgraha).${ }^{27}$

Although none employed fasting so masterfully as Gandhi, many prominent public figures in North America have also undertaken hunger strikes to advance a social or political cause. Recent examples include Jack Kevorkian protesting laws banning physician-assisted suicides during his trial; Randall Robinson, a social activist, and Katherine Dunham, a pioneer of American modern dance, protesting United States policy toward Haiti; Tony Hall, a Democratic congressman from Dayton, Ohio, protesting a decision of the House of Representatives to abolish the select Committee on Hunger, and so on. Hunger strikes have also been employed by people who lack the notoriety of these examples, but nevertheless by fasting can exert power from an otherwise powerless position.

A provocative study by Maud Ellmann considers the distinction between respectable forms of self-starvation as social protest and anorexia nervosa as a clinical disorder. Referring to the example of hunger strikers protesting British rule in Ireland, she recalls, "A few years ago, a friend told me he was going to a wake in Belfast for a woman who had been a hunger striker in Armagh, the principal camp for female terrorists in Northern Ireland. She had survived the hunger strike, and had even been released from prison, but had died within the year of anorexia nervosa." 22 The example draws into focus the question of how fasting may function as a social protest and how it may also acquire its own momentum independent of the initial motive. A reviewer puzzled over the similar features of these distinctive phenomena: What ... is the relationship between these two forms of self- 
starvation, so similar in their physical effects and yet so incommensurable in their meanings? Do hunger-strikers lose their appetite for food once they have feasted on the void and become, in Emily Dickinson's words 'inebriate of air'? Or are anorexic women really hunger-strikers in disguise, defying the patriarchal values that confine their sex as rigidly as any prison? ${ }^{62}$

Both as sacrifice and pathology, eating and starving are social acts capable of affecting families and societies. To ignore that element of social protest and spiritual purification, which are defining features of other contexts in which fasting and self-starvation occur, obscures core features of disordered eating behavior that are socially and clinically significant.

Agenda for Cultural Research and Clinical Assessment

Cross-cultural studies show that eating disorders may not be represented adequately by the current diagnostic criteria of DSM-IV. Social analysis that attributes the increase of eating disorders to the increasing influence of Western ideals of feminine beauty may have inadvertently defined culturespecific criteria incorporating fear of fatness and distorted body image, hampering the cross-cultural studies needed most to clarify culturally valid core features of anorexia nervosa and bulimia nervosa.

Notwithstanding open questions from cultural and historical studies about the nosological status of eating disorders, AN and BN are serious conditions that will continue to challenge mental health professionals. Because they are identified increasingly among cultural groups where they present with distinctive features, the need to clarify professional concepts and local meanings of these disorders has become a top priority. The following agenda will help to achieve these aims:

(1) Recognizing the need for diagnostic criteria more suitable for cross-cultural comparisons, criteria for anorexia nervosa such as those proposed by Sing Lee should be used as complements to the DSM-IV criteria (Table 2). Comparing evaluations of patients with respect to both criteria sets will clarify questions about the significance and cultural specificity of 
"fear of gaining weight," distorted body image, and other features of the disorder from experience in non-Western clinics.

(2) Research and clinical case studies of eating disorders should carefully attend to elements of the cultural formulation proposed in Appendix I of DSM-IV. These include a narrative summary to specify the cultural identity of the affected individual, cultural explanations of the illness, cultural features of the psychosocial environment, cultural elements of the relationship between the individual and the clinician, and an overall cultural assessment for diagnosis and care.

(3) Systematic methods for relating local meanings and professional diagnoses are required to understand the experience of eating disorders among affected individuals, their families, and those who treat them. Instruments that combine qualitative and quantitative research orientations, such as the Explanatory Model Interview Catalogue (EMIC), provide clinical ethnographic insights that clarify the cultural epidemiology of these disorders. ${ }^{71,16 \#, 72}$

(4) Field studies in communities of persons at risk for eating disorders or otherwise engaged in fasting (e.g., college students, dancers, gymnasts, people who are currently or were recently fasting or about to fast) are needed to clarify values concerning body image; the meanings of eating and dieting as social and personal activities; peer group influences on eating, dieting, and binging behaviors; perceived impact on others; and the range of normal, disturbed, and disordered eating behaviors.

Clinical experience and research have moved the field toward greater recognition and differentiation of eating disorders as independent categories of mental disorder. Shorter's historical analysis, however, suggests that it may be useful to reconsider the relationship of $\mathrm{AN}$ and $\mathrm{BN}$ to the broader class of somatoform disorders. Also, by conferring legitimacy on this socially and culturally constructed disorder, mental health professionals may have seriously underestimated their unanticipated influence in propagating eating disorders with publicity aimed at preventing and curing them. Inasmuch as it offers an alternative or complement to the prevailing cultural hypothesis, which focuses on the impact of Western esthetics rather than the sociology of health care institutions, and has important implications for policy and 
publicity about eating disorders, the question of how culture and Westernization affect the epidemiology and experience of eating disorders also requires further study. 
$\underline{\text { REFERENCES }}$

1. American Psychiatric Association: Practice guidelines for eating disorders. Am J Psychiatry 150(2):207-228, 1993

2. American Psychiatric Association: Diagnostic and Statistical Manual of Mental Disorders, Fourth Edition. Washington, DC, American Psychiatric Association, 1994

3. American Psychiatric Association: Diagnostic and Statistical Manual of Mental Disorders, Third Edition, Revised. Washington, DC, American Psychiatric Association, 1987

4. American Psychiatric Association: Diagnostic and Statistical Manual of Mental Disorders, Third Edition. Washington, DC, American Psychiatric Association, 1980

5. American Psychiatric Association: Diagnostic and Statistical Manual of Mental Disorders, Second Edition. Washington, DC, American Psychiatric Association, 1968

6. Banks CG: "Culture" in culture-bound syndromes: The case of anorexia nervosa. Soc Sci Med 34:867-884, 1992

7. Bemporad JR, Ratey JJ, O'Driscoll G, et al: Hysteria, anorexia, and the culture of self-denial. Psychiatry 51(1):96-103, 1988

8. Bhadrinath BR: Anorexia nervosa in adolescents of Asian extraction. Br J Psychiatry 156:565-568, 1990

9. Boddy J: Body politics: Continuing the anticircumcision crusade. Medical Anthropology Quarterly 5(1):15-17, 1991

10. Bruch H: Four decades of eating disorders. In Garner DM, Garfinkel PE (eds): Handbook of Psychotherapy for Anorexia Nervosa and Bulimia. New York, Gilford, 1985, p 7-18

11. Bruch H: Anorexia Nervosa: Therapy and theory. Am J Psychiatry $139(12): 1531-1538,1982$

12. Bruch H: The Golden Cage: The Enigma of Anorexia Nervosa. Cambridge, Harvard University Press, 1978

13. Brumberg JJ: Fasting Girls: The Emergence of Anorexia Nervosa as a 
Modern Disease. Cambridge, Harvard University Press, 1988

14. Calabrese LH, Kirkendall DT: Nutritional and medical considerations in dancers. Clinics in Sports Medicine 2(3):539-548, 1983

15. Casper RC: On the emergence of bulimia as a syndrome: A historical view. Int J Eating Dis 2:3-16, 1983

16. Channabasavanna SM, Raguram R, Weiss MG, et al: Ethnography of psychiatric illness: A pilot study. NIMHANS Journal 11(1):1-10, 1993

17. Crisp AH, Hsu LK, Harding B, et al: Clinical features of anorexia nervosa: A study of a consecutive series of 102 female patients. J Psychosom Res 24(3-4):179-191, 1980

18. Davis C, Yager J: Transcultural aspects of eating disorders: A critical literature review. Culture, Medicine and Psychiatry 16:377394,1992

19. Deutsch F, et al: Anorexia nervosa: A psychosomatic entity. Psychosomatic Medicine 2:1-16, 1940

20. DiNicola VF: Anorexia multiforme: Self-starvation in historical and cultural context. Parts 1 and 2. Trans Psychiatric Res Rev 27:165-196 and $27: 245-286,1990$

21. Eastwell HD: A pica epidemic: A price for sedentarism among Australian ex-hunter-gatherers. Psychiatry 42:264-273, 1979

22. Ellman M: The Hunger Artists: Starving, Writing, and Imprisonment. Cambridge, Harvard University Press, 1993

23. Fahy TA, Robinson PH, Russell GF, et al: Anorexia nervosa following torture in a young African woman. Br J Psychiatry 153:385-387, 1988

24. Fallon P, Katzman MA, Wooley SC: Feminist Perspectives on Eating Disorders. New York, Guilford, 1994

25. Fichter MM, Weyerer S, Sourdi S, et al: The epidemiology of anorexia nervosa: A comparison of Greek adolescents living in Germany and Greek adolescents living in Greece. In Darby $\mathrm{P}$, et al (eds): Anorexia Nervosa: Recent Developments in Research. New York, Alan R. Liss, 1983, p 95-105

26. Gandhi DH, Appaya MP, Machado T: Anorexia nervosa in Asian children. Br J Psychiatry 159:591-592, 1991 
27. Gandhi, MK: An Autobiography: The Story of My Experiments with Truth. Boston, Beacon Press, 1957.

28. Garner DM: Pathogenesis of anorexia nervosa. Lancet 341:1631-1635, 1993

29. Garner DM, Garfinkel PE: Socio-cultural factors in the development of anorexia nervosa. Psychological Medicine 10(4):647-656, 1980

30. Gilligan C: In a Different Voice. Cambridge, Harvard University Press, 1982

31. Gordon D: Female circumcision and genital operations in Egypt and the Sudan: A dilemma for medical anthropology. Medical Anthropology Quarterly $5(1): 3-14,1991$

32. Herzog DB, Newman KL, Warshaw M: Body image dissatisfaction in homosexual and heterosexual males. J Nerv Ment Dis 179:356-359, 1991

33. Holderness CC, Brooks-Gunn J, Warren MP: Eating disorders and substance use: A dancing vs a nondancing population. Medicine \& Science in Sports \& Exercise 26(3):297-302, 1994

34. Hsu LK, Lee $\mathrm{S}$ : Is weight phobia always necessary for a diagnosis of anorexia nervosa? Am J Psychiatry 150(10):1466-1471, 1993

35. Hsu LK: Are the eating disorders becoming more common in blacks? Int J of Eating Disorders 6(1):113-124, 1987

36. Kennedy SH, Garfinkel $\mathrm{PE}$ : Advances in diagnosis and treatment of anorexia nervosa and bulimia nervosa. Can J Psychiatry 37(5):309-315, 1992

37. Khandelwal SK, Saxena S: Anorexia nervosa in people of Asian extraction. Br J Psychiatry 157:784, 1990

38. King MB, Bhugra D: Eating disorders: Lessons from a cross-cultural study. Psychological Medicine 19:955-958, 1989

39. Kinzl JF, Traweger C, Guenther V, et al: Family background and sexual abuse associated with eating disorders. Am J Psychiatry 151(8):11271131

40. Kleinman A: Depression, somatization, and the "new cross-cultural psychiatry." Soc Sci Med 11(1):3-10, 1977

41. Lacey EP: Broadening the perspective of pica: Literature review. 
Public Health Reports - Hyattsville 105(1):29-35, 1990

42. Lee S: The Diagnostic Interview Schedule and anorexia nervosa in Hong Kong. Arch Gen Psychiatry 51(3):251-252, 1994

43. Lee S, Ho TP, Hsu LK: Fat phobic and non-fat phobic anorexia nervosa: A comparative study of 70 Chinese patients in Hong Kong. Psychological Medicine 23:999-1017, 1993

44. Lee S: Reply to Drs. Joel Yager and Cindy Davis. Trans Psychiatric Res Rev $30: 296-304,1993$

45. Lee S: Anorexia nervosa in Hong Kong: A Chinese perspective. Psychological Medicine 21(3):703-711, 1991

46. Littlewood R: From categories to contexts: A decade of the "new crosscultural psychiatry." Br J Psychiatry 156:308-327, 1990

47. Littlewood R, Lipsedge M: The butterfly and the serpent: Culture, psychopathology, and biomedicine. Culture, Medicine and Psychiatry $11: 289-335,1987$

48. Lucas AR, Beard CM, O'Fallon WM, et al: Anorexia nervosa in Rochester, Minnesota: A 45-Year Study. Mayo Clin Proc 63:433-442, 1988

49. Markantonakis A: Anorexia nervosa in people of Asian extraction. Br J Psychiatry $157: 783-784,1990$

50. Masson JM: The psychology of the ascetic. J Asian Studies 35(4):611625,1976

51. Mumford DB, Whitehouse AM, Platts M: Sociocultural correlates of eating disorders among Asian schoolgirls in Bradford. Br J Psychiatry 158:2228,1991

52. Mumford DB, Whitehouse AM: Increased prevalence of bulimia nervosa among Asian schoolgirls. Br Med Journal 297:718, 1988

53. Mumford DB, Whitehouse AM: Bulimia nervosa among Asian schoolgirls. Br Med Journal 297:1404, 1988

54. Nagel $\mathrm{KL}$, Jones $\mathrm{KH}$ : Sociological factors in the development of eating disorders. Adolescence 27(105):107-113, 1992

55. Orbach S: Hunger Strike. New York, Norton, 1986

56. Pate JE, Pumariega AJ, Hester C, Garner D: Cross-cultural patterns in eating disorders: A review. J Am Acad Child Adolesc Psychiatry 
$31(5): 802-809,1992$

57. Patton GG: Mortality in eating disorders. Psychol Med 18:947-951, 1988

58. Prince R: The concept of culture-bound syndromes: Anorexia nervosa and brain-fag. Soc Sci Med 21(2):197-203, 1985

59. Pumariega AJ, Edwards P, Mitchell CB: Anorexia nervosa in black adolescents. J Am Acad Child Adolesc Psychiatry 23(1):111-114, 1984

60. Ritenbaugh $\mathrm{C}$ : Obesity as a culture-bound syndrome. Culture, Medicine and Psychiatry $6(4): 347-364,1982$

61. Rorty M, Yager J, Rossotto E: Childhood sexual, physical, and psychological abuse in bulimia nervosa. Am J Psychiatry 151(8):11221126,1994

62. Russell M: Feasting on the void: Review of Maud Ellmann, The Hunger Artists. Irish Times, 15 september 1993.

63. Scheper-Hughes N, Lock MM: The mindful body: A prolegomenon to future work in medical anthropology. Medical Anthropology Quarterly 1(1):6-41, 1987

64. Schwartz D, Thompson M, Johnson C: Anorexia nervosa and bulimia: The sociocultural context. International Journal of Eating Disorders $1(3): 20-27,1982$

65. Shorter E: From the Mind into the Body: The Cultural Origins of Psychosomatic Symptoms. New York, Free Press, 1994

66. Steiger H: Anorexia nervosa: Is it the syndrome or the theorist that is culture- and gender-bound? Trans Psychiatric Res Rev 30:347-358, 1993

67. Steiner-Adair C: The body politic: Normal female adolescent development and the development of eating disorders. J Am Acad Psychoanalysis $14(1): 95-114,1986$

68. Swartz L: Anorexia nervosa as a culture-bound syndrome. Soc Sci Med $20(7): 725-730,1985$

69. Toubia N: Female circumcision as a public health issue. New Engl J Med $331(11): 712-716,1994$

70. Ware N, Weiss MG: Sociocultural perspectives on psychiatric diagnosis: The case of neurasthenia. Trans Psychiatric Res Rev 31:101-124, 1994 
71. Weiss MG, Raguram R, Channabasavanna SM: Cultural dimensions of psychiatric diagnosis: Comparing DSM-III-R and illness explanatory models in South India. Br J Psychiatry. In Press

72. Weiss MG, Doongaji DR, Siddhartha S, et al: The explanatory model interview catalogue (EMIC): Contribution to cross-cultural research methods from a study of leprosy and mental health. Br J Psychiatry $160(6): 819-830,1992$

73. World Health Organization (WHO): ICD-10. International statistical classification of diseases and related health problems. Tenth Edition. Geneva, World Health Organization, 1992.

74. World Health Organization (WHO): ICD-9. Manual of the International Statistical Classification of Diseases, Injuries, and Causes of Death. 9th Edition. Geneva, World Health Organization, 1977

75. Yap PM: Words and things in comparative psychiatry with special reference to the exotic psychoses. Acta Psychiat Scand 38:163-169, 1962 
Social and Psychological Contexts of Eating Disorders

Identified from Social Research and Clinical Experience

\section{Societal}

1. Overvaluation of thinness as a cultural ideal of feminine beauty

2. Rapid social changes from Westernization, urbanization, or immigration

3. Publicity defining eating disorders as legitimate medical conditions

Social

4. Example of peers and role models

5. Disturbed family dynamics and struggle for control

6. Enhancing performance in dance and sport

\section{Psychological}

7. Establishing sense of identity and autonomy

8. Expression of religious piety according to ascetic ideal

9. Forestalling sexual maturity and adulthood

10. Momentum of fasting regardless of initial motive 
Table 2

DSM-IV and Sing Lee's "Culture-Free" Diagnostic Criteria

for Anorexia Nervosa

\begin{tabular}{|c|c|c|}
\hline DSI & $-\mathrm{IV}^{ \pm}$ & Revised "CuLture-Free" Criteria" \\
\hline $\bar{A}$. & $\begin{array}{l}\text { Refusal to maintain body weight at } \\
\text { or above a minimally normal weight } \\
\text { for age and height (e.g., weight } \\
\text { loss leading to maintenance of body } \\
\text { weight less than 85\% of that } \\
\text { expected; or failure to make } \\
\text { expected weight gain during period } \\
\text { of growth, leading to body weight } \\
\text { less than 85\% of that expected). }\end{array}$ & $\begin{array}{l}\text { A. Weight loss of } 15 \% \text { or more of } \\
\text { weight expected for height. }\end{array}$ \\
\hline 3. & $\begin{array}{l}\text { Intense fear of gaining weight or } \\
\text { becoming fat, even though } \\
\text { underweight. }\end{array}$ & $\begin{array}{l}\text { B. The weight loss or maintenance of a } \\
\text { low body weight is self-induced by } \\
\text { a restriction of food intake, which } \\
\text { may be accompanied by: (a) } \\
\text { excessive exercise, (b) self- } \\
\text { induced vomiting, (c) self-induced } \\
\text { purging, or (d) use of appetite } \\
\text { suppressants and/or diuretics. }\end{array}$ \\
\hline C. & $\begin{array}{l}\text { Disturbance in the way in which } \\
\text { one's body weight or shape is } \\
\text { experienced, undue influence of } \\
\text { body weight or shape on self- } \\
\text { evaluation, or denial of the } \\
\text { seriousness of the current low body } \\
\text { weight. }\end{array}$ & $\begin{array}{l}\text { In response to others attempts to } \\
\text { make her/him increase food intake, } \\
\text { the patient uses complaints such as } \\
\text { fear of fatness, abdominal } \\
\text { bloating, loss of appetite, no } \\
\text { hunger, distaste for food, and/or } \\
\text { even "don't know" to resist such } \\
\text { attempts. }\end{array}$ \\
\hline D. & $\begin{array}{l}\text { In postmenarcheal temales, } \\
\text { amenorrhea, i.e., the absence of at } \\
\text { least three consecutive menstrual } \\
\text { cycles. (A woman is considered to } \\
\text { have amenorrhea if her periods } \\
\text { occur only following hormone, e.g., } \\
\text { estrogen, administration.) }\end{array}$ & $\begin{array}{l}\text { Amenorrhea in temale or loss of } \\
\text { libido in male. }\end{array}$ \\
\hline & & $\begin{array}{l}\text { No other known disorder is found } \\
\text { account for the weight loss. }\end{array}$ \\
\hline
\end{tabular}

1. American Psychiatric Association: Diagnostic and Statistical Manual of Mental Disorders, Fourth Edition. Washington, DC, American Psychiatric Association, 1994, p 544-545

2. Lee S: Reply to Drs. Joel Yager and Cindy Davis. Trans Psychiatric Res Rev 30:296-304, 1993, p 300 